\title{
Sex Difference in the Range of Pelvic Tilt in Sitting and Standing Among Korean Young Adults
}

\author{
Jangwhon Yoon, PhD, PT \\ Laboratory of Biomechanics (LABIO), Department of Physical Therapy, Hoseo University, Asan, Korea
}

\author{
Article Info \\ Received March 20, 2020 \\ Revised April 14, 2020 \\ Accepted April 24, 2020

\section{Corresponding Author \\ Jangwhon Yoon \\ E-mail: jyoon@hoseo.edu \\ https://orcid.org/0000-0001-8616-1566}

\section{Key Words}

Muscle length

Pelvic tilt

Range of motion

Sex characteristics

Testing position
Background: The range of pelvic tilt is one of modifiable risk factors in preventing the lower back pain.

Objects: The purpose of this study were to compare the range of pelvic tilt motion by testing position and sex.

Methods: One hundred five young adults (61 females and 44 males) agreed to participate in measuring the anterior and posterior pelvic tilt with the PALM (Palpation Meter) in sitting and standing. The range of pelvic tilt motion was defined as the difference between the pelvic anterior and posterior tilt angles.

Results: In general, the anterior pelvic tilt was greater $(p<0.01)$ in standing than in sitting and the posterior pelvic tilt was lesser $(p<0.01)$ in sitting than in standing. The anterior pelvic tilt in sitting and standing was greater $(p<0.01)$ in the females than in the males. However, the effect of sex on the posterior pelvic tilt was only significant in sitting $(p<0.01)$, but not in standing $(p=0.78)$. The range of pelvic tilt was greater $(p=0.03)$ in sitting but not significantly $(p=0.07)$ affected by the sex.

Conclusion: The pelvic tilt motion in these young adults showed large variability and further studies are needed to understand better its relationship to the prevalence of the lower back disorders.

\section{INTRODUCTION}

The pelvis is core component of human posture and movement. Tightness or weakness of adjacent muscles can affect the neutral angle and the maximal range of pelvic motion [1]. Pelvic position can directly influence lumbar spine alignment, which is considered a risk factor in low back pain [2] Excessive anterior pelvic tilt has been suggested to increase loading on the lumbar spine [3]. Altered lumbopelvic movement has been reported in patients with low back pain [4]. The range of pelvic tilt was considered as a modifiable factor in preventing the lower back pain [1].

The lumbar curve was altered by the pelvic tilt: anterior tilt increased the depth of the lumbar curve and posterior tilt decreased the depth of the lumbar curve [5,6]. The normal neutral pelvic angle in standing appears to be sex dependent, with mean values of approximately $9^{\circ}$ for males and $12^{\circ}$ for females [7]. Majority of asymptomatic males and females had slightly anterior tilt in standing but no significant sex difference in the resting pelvic angle [8]. People wearing tight jeans have limited pelvic movement and decreased erector spinae activity during deep trunk flexion at workplaces, and further strain their interspinous ligaments was cautioned [9]. Muscular tightness and shortening of the erector spinae and hip flexors, and elongation and weakening of the abdominals and gluteals have been suggested to result in greater anterior pelvic angle [10-12]. Hamstring tightness measured with the active knee extension method showed a moderate correlation with pelvic range of motion movement [13].

The patients with low back pain often demonstrate a malalignment of the pelvis due to asymmetry in lower limb posture, restricted motion at the hip joint, weak gluteal muscles, and transversus abdominis, but tight hamstring, psoas muscles and quadratus lumborum [14]. Increased maximal anterior pelvic tilt in standing had increased the angle of lumbar lordosis and increased the degree of posterior pelvic tilt decreased the 
angle of lumbar lordosis [15]. The chronic low back pain group had a significantly smaller pelvic tilt $\left(57.0^{\circ} \pm 15.3^{\circ}\right)$ and a total trunk flexion $\left(82.2^{\circ} \pm 39.7^{\circ}\right)$ than the asymptomatic group $\left(66.7^{\circ} \pm 19.4^{\circ}\right.$ and $104.6^{\circ} \pm 29.3^{\circ}$ respectively), but a not significantly different lumbar range of motion $\left(79.8^{\circ} \pm 34.3^{\circ}\right.$ and $64.5^{\circ} \pm 34.8^{\circ}$ ) using inclinometer at L5-S1 and T12-L1 during trunk forward bending task [13].

Age and sex, hamstring muscle tightness, feet position, muscle fatigue, movement speed and external loading as well phase of motion found to affect various aspects of lumbopelvic movement during trunk forward bending in a systemic review [1]. There has been a considerable controversial sex difference in the neutral pelvic tilt in standing $[1,7,8,16,17]$. Sex difference in lumbopelvic rhythm has been reported due to different spinal stability [18] in females.

Majority of previous studies regarding pelvic tilt has focused on the static neutral angle in standing [5,15,19-21] or on the dynamic angular displacement as a part of the lumbosacral coordination during deep bending forward [1,9,22-24]. This study focused on the active range of pelvic motion in sitting and standing which is calculated from the maximal voluntary anterior and posterior tilt angle. The active range of pelvic motion in standing and sitting can be a fundamental dynamic variable easily assessed in a clinical setting. The purpose of this study was to compare the range of pelvic tilt measured in standing and sitting position between the young male and the female participants.

\section{MATERIALS AND METHODS}

\section{Participants}

One hundred five volunteers (61 females and 44 males) without any on-going pain or history of major injury or surgery in the spine and lower limbs were participated in this study. Participants signed an Institutional Review Board approved (approval No. 1041231-190219-HR-089-03) consent form. The characteristics of participants is summarized in the Table 1.

\section{Equipment}

The PALM device (Palpation Meter; Performance Attainment Associates, St. Paul, MN, USA) was used to measure the sagittal pelvic tilt angle. It consists of an inclinometer and two caliper arms with a hole at the end of each caliper arm for accurate palpation. Intraclass correlation coefficient values ( $95 \%$ con- fidence Interval), standard error of measurement and smallest detectable change values for intra-rater reliability of sagittal pelvic position was 0.92 (0.80-0.97), 0.7 and 1.8 degrees in standing and 0.90 (0.74-0.96), 1.5 and 4.0 degrees in sitting [20].

\section{Procedure}

The maximal pelvic anterior and posterior tilt angles were measured at the end of active range of motion on the dominant side in sitting and standing. The order of measurement was randomized using the random formula in Excel (Microsoft, Redmond, WA, USA). Participants were asked to wear a short pants to visually inspect the alignment of lower extremities. They stood or sat with their feet parallelly apart $30 \mathrm{~cm}$ to control the ankle and hip rotation between trials [19]. A height adjustable stool was used for sitting and the height was adjusted to keep the knee joints in 90 degrees. They kept their arms crossed over the chest while a single examiner palpated the anterior superior iliac spines (ASIS) and posterior superior iliac spines (PSIS). The palpation procedure was done as described by Herrington [8]. The angle between ASIS and PSIS was measured three times and averaged [5]. When the erect trunk posture was not established, the participant was instructed and remeasured. Positive values were related to anterior pelvic tilt, while negative values were related to posterior pelvic tilt. Prior to measure, the examiner explained the pelvic tilt motion with demonstration and they practiced both anterior and posterior pelvic tilt motion at least 10 times for familiarization. The verbal instruction for anterior pelvic tilt was "bring your imaginary tail up as much as possible" and "bring it down and forward as much as possible" for posterior pelvic tilt.

\section{Data Analysis}

Outcome variables are the pelvic anterior and posterior tilt angles and the range of pelvic tilt motion (the difference between the pelvic anterior and posterior tilt angles). For statistical analyses, repeated-measures ANOVA was used to test

Table 1. The characteristics of participants $(\mathrm{N}=105)$

\begin{tabular}{lrrc}
\hline \multicolumn{1}{c}{ Variable } & $\begin{array}{c}\text { Female } \\
(\mathrm{n}=61)\end{array}$ & $\begin{array}{c}\text { Male } \\
(\mathrm{n}=44)\end{array}$ & $\begin{array}{c}\text { Total } \\
(\mathrm{N}=105)\end{array}$ \\
\hline Age $(\mathrm{y})$ & $22.9 \pm 1.4$ & $23.0 \pm 1.9$ & $22.9 \pm 1.6$ \\
Height $(\mathrm{cm})$ & $161.5 \pm 5.0$ & $174.8 \pm 5.1$ & $167.1 \pm 8.2$ \\
Weight $(\mathrm{kg})$ & $54.8 \pm 7.7$ & $69.9 \pm 9.9$ & $61.1 \pm 11.5$ \\
Body mass index $\left(\mathrm{kg} / \mathrm{m}^{2}\right)$ & $21.0 \pm 2.9$ & $22.8 \pm 2.9$ & $21.8 \pm 3.0$ \\
\hline
\end{tabular}


whether the outcome variables were associated with the testing position (a within-subject effect, sitting and standing) and sex (a between-subject effect). In case of significant interaction between sex and testing position, sitting and standing data were separately tested using the independent t-test. All analyses were conducted with SPSS version 20 (IBM Co., Armonk., NY, USA) using a significance level of alpha $=0.05$.

\section{RESULTS}

Anterior pelvic tilt angle of the male participants was $8.4^{\circ} \pm$ $5.2^{\circ}$ in standing and $-2.5^{\circ} \pm 9.0^{\circ}$ in sitting, while, in the female participants, $10.9^{\circ} \pm 5.4^{\circ}$ in standing and $2.4^{\circ} \pm 7.3^{\circ}$ in sitting (Figure 1). The main effects of position $(F=125.62, p<0.01)$ and of sex $(F=12.45, p<0.01)$ on the anterior pelvic tilt were both statistically significant. The interaction effect between position and sex were not significant $(\mathrm{F}=1.91, \mathrm{p}=0.17)$.

Posterior pelvic tilt angle of the male participants was $-6.5^{\circ}$ $\pm 3.2^{\circ}$ in standing and $-19.8^{\circ} \pm 7.0^{\circ}$ in sitting, while for the females $-6.7^{\circ} \pm 3.9^{\circ}$ in standing and $-15.6^{\circ} \pm 6.7^{\circ}$ in sitting (Figure 2). The main effects of position $(F=261.25, p<0.01)$ and of sex $(F=5.4, p=0.02)$ on the posterior pelvic tilt were both statistically significant. The interaction effect between position and sex were significant $(F=9.98, p<0.01)$. When separately analyzed using the independent t-test, the effect of sex on the posterior pelvic tilt was significant in sitting $(t=3.04$, $\mathrm{p}<0.01)$, but not in standing $(\mathrm{t}=-0.28, \mathrm{p}=0.78)$.

Pelvic range of motion of the male participants was $14.9^{\circ}$ $\pm 5.0^{\circ}$ in standing and $17.3^{\circ} \pm 5.5^{\circ}$ in sitting, while in female $17.6^{\circ} \pm 5.2^{\circ}$ in standing and $18.1^{\circ} \pm 6.9^{\circ}$ in sitting (Figure 3). The main effects of testing position $(F=5.17, p=0.03)$ was statistically significant but the effect of $\operatorname{sex}(F=3.29, p=0.07)$

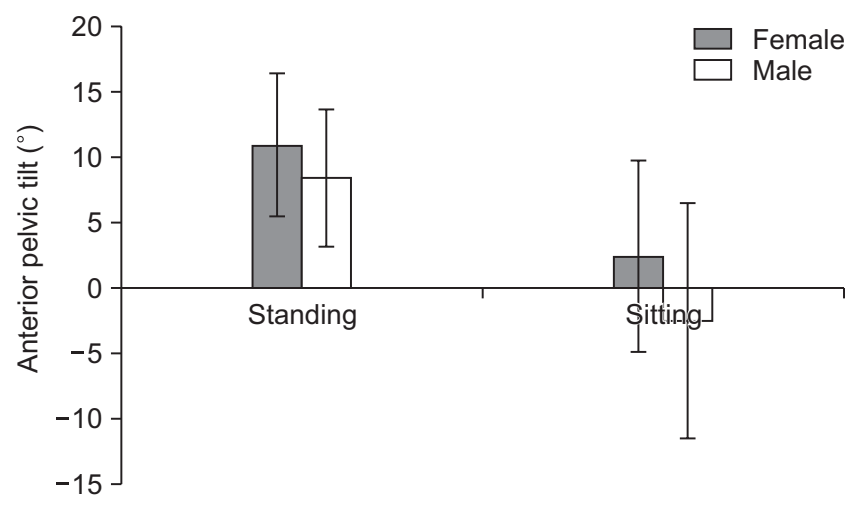

Figure 1. Anterior pelvic tilt $\left({ }^{\circ}\right)$ in standing and sitting by sex. on the pelvic range of motion was not statistically significant. The interaction effect between position and sex were not significant $(\mathrm{F}=2.49, \mathrm{p}=0.12)$.

\section{DISCUSSION}

The range of pelvic tilt varies by testing position and sex. The anterior pelvic tilt was greater in standing than in sitting and the posterior pelvic tilt was lesser in sitting than in standing. The anterior pelvic tilt in sitting and standing was greater in the females than in the males. However, the effect of sex on the posterior pelvic tilt was only significant in sitting, but not in standing. The range of pelvic tilt was greater in sitting but not significantly affected by the sex. The sagittal pelvic motion in these young adults demonstrated fairly large variability and the testing position and sex must be considered for assessing the pelvic tilt motion accurately in a clinical setting.

The marginal mean of anterior pelvic tilt in both male and female together was $9.5^{\circ} \pm 8.8^{\circ}$ greater in standing $\left(9.9^{\circ} \pm\right.$ $\left.5.5^{\circ}\right)$ than in sitting $\left(0.4^{\circ} \pm 8.4^{\circ}\right)$ and the posterior pelvic tilt

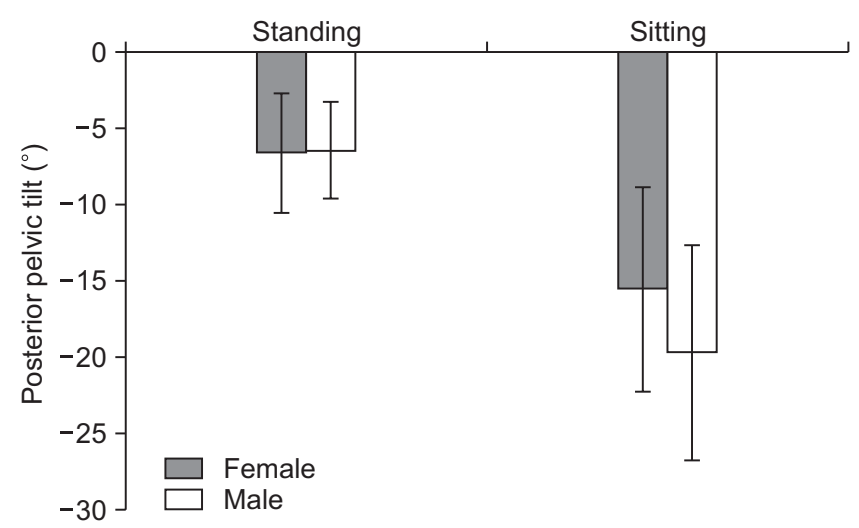

Figure 2. Posterior pelvic tilt $\left({ }^{\circ}\right)$ in standing and sitting by sex.

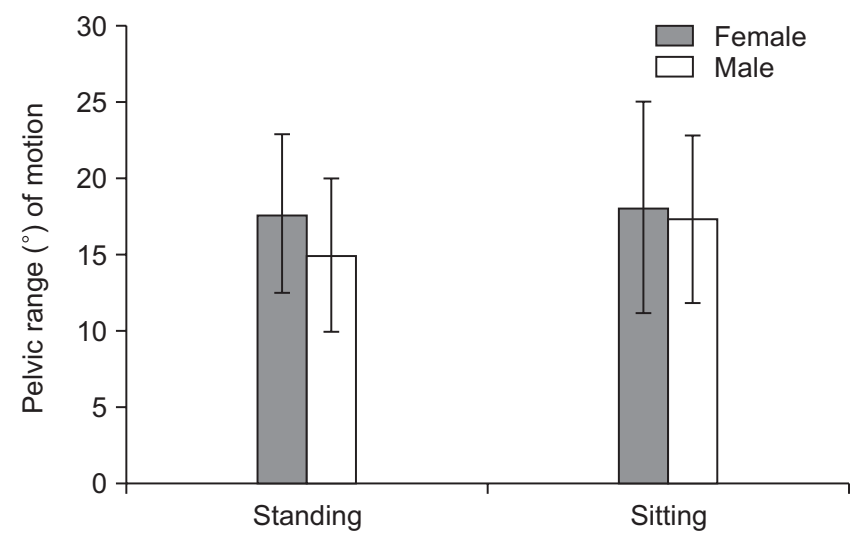

Figure 3. Pelvic range $\left({ }^{\circ}\right)$ of motion in standing and sitting by sex. 
was $10.7^{\circ} \pm 7.2^{\circ}$ lesser in sitting $\left(-17.4^{\circ} \pm 7.1^{\circ}\right)$ than in standing $\left(-6.6^{\circ} \pm 3.6^{\circ}\right)$. Relatively to standing, in sitting position, the hip joints are in flexed position, the pelvis is tilted posteriorly, and consequently the lumbar lordosis is decreased. Decreased lumbar lordosis from the posterior pelvic tilt in sitting can limit the load distributing and absorbing function of lumbar spine. Spine, pelvis and lower extremity movements are closely interconnected due to the closed kinematic chain [25]. For example, induced calcaneal eversion using a wedge under the hindfoot tilted the pelvis anteriorly [24]. Increased posterior pelvic rotation during hip flexion can cause excessive lumbar spine movement and increase lumbar spine stress $[4,13,26]$.

The range of pelvic tilt was $1.2^{\circ} \pm 6.2^{\circ}$ greater in sitting $\left(17.7^{\circ} \pm 6.3^{\circ}\right)$ than in standing $\left(16.5^{\circ} \pm 5.3^{\circ}\right)$. The range of pelvic tilt of this study was slightly less than those (about $20^{\circ}$ in healthy group no exact value reported) measured with electromechanical units [5]. The possible reasons for the increased range of pelvic motion in sitting are the larger base of support and relatively lower center of mass from the base of support, so the participants were able to tilt their pelvis further without worrying about the balance. The amount of pelvic tilt was not affected by whether knees were extended or flexed approximately 10 degrees [5]. In a forward bending study [27], the mean angle of pelvic tilt was $15.5^{\circ} \pm 6.9^{\circ}$ and no association was found between hamstring muscle length and the total angle of pelvic tilt in people with extensibility of the hamstrings within normal limits.

Roughly speaking, pelvis is posteriorly tilted in the males and more anteriorly tilted in the females. In standing, the maximal active anterior pelvic tilt (Figure 1) was $2.5^{\circ}$ greater in the females $\left(10.9^{\circ} \pm 5.2^{\circ}\right)$ than in the males $\left(8.4^{\circ} \pm 5.2^{\circ}\right)$, and in sitting, $4.9^{\circ}$ greater in the females $\left(2.4^{\circ} \pm 7.3^{\circ}\right)$ than in the males $\left(-2.5^{\circ} \pm 9.0^{\circ}\right)$. Posterior pelvic tilt of the male participants was $-6.5^{\circ} \pm 3.2^{\circ}$ in standing and $-19.8^{\circ} \pm 7.0^{\circ}$ in sitting, while for the females $-6.7^{\circ} \pm 3.9^{\circ}$ (not statistically different) in standing and $-15.6^{\circ} \pm 6.7^{\circ}\left(4.1^{\circ}\right.$ smaller than the male ones) in sitting (Figure 2). The range of pelvic tilt was not significantly $(p=0.07)$ affected by the sex $\left(17.9^{\circ} \pm 6.0^{\circ}\right.$ in female and $16.1^{\circ} \pm 5.2^{\circ}$ in male). Majority of males and females had slightly anterior tilt in standing but no significant sex difference in a neutral pelvic angle study [8]. In trunk forward bending, there was no significant sex difference in pelvic tilt $\left(64.6^{\circ} \pm 14.6^{\circ}\right.$ and $59.7^{\circ}$ $\left.\pm 15.3^{\circ}\right)$, total trunk flexion $\left(97.6^{\circ} \pm 35.3^{\circ}\right.$ and $\left.98.5^{\circ} \pm 37.4^{\circ}\right)$ and lumbar range of motion $\left(67.6^{\circ} \pm 34.8^{\circ}\right.$ and $\left.75.6^{\circ} \pm 35.1^{\circ}\right)$ when measured with inclinometer at L5-S1 and T12-L1 [13]. The range of anterior tilt of the pelvis on the thigh was less for the men with short hamstrings $\left(52^{\circ} \pm 9^{\circ}\right)$ than for the men without short hamstrings $\left(72^{\circ} \pm 4^{\circ}\right)(\mathrm{p}<0.001)$, but the lumbar flexion range of motion was not significantly different during toe-touching task [21]. Kienbacher et al. [28] reported that hip range of motion from standing to the maximum flexion position is significantly lower in males than in females. Sex difference in hamstring flexibility is common [1,7,29,30]. Reduced hamstring flexibility is related to decreased anterior pelvic tilt angles as in the male participants of this study. The decreased anterior pelvic tilt angles can overload the spine during trunk forward flexion [1,13,31] and manual materials handling [32]. In a longitudinal study [31], a significant decrease in the level of hamstring stiffness was recorded in the experimental group accompanied by an increase in anterior pelvic tilt.

Limitations of the current study include a young nonimpaired population and findings relating to more elderly, or those in lower back pain or impaired, may differ from the current findings. Measuring the pelvic angle with PALM is easy, simple, and quick but it is static and uniplanar. Analysis was limited to the sagittal plane and more sophisticated 3-dimensional kinematics would provide a more detailed analysis regarding pelvic tilt. Factors affecting the pelvic range of motion, such as the hamstring muscle length and hip range of motion were not measured in this study. In addition, there were no objective measure to control the unwanted adjacent joint motions other than visual inspection. Although this study was limited to healthy subjects, clinicians should be aware that when addressing pelvis and lower back dysfunction, foot alignment should be examined as a contributing factor. The pelvic tilt motion has fairly large variability even though the participants were young and healthy. There should be more studies to figure out the influence of pelvic orientation on whole-body posture and body mechanics. Furthermore, studies are needed to understand better its relationship to the prevalence of the lower back disorders.

\section{CONCLUSIONS}

The purpose of this study was to compare the range of pelvic tilt motion by testing position and sex. The anterior pelvic tilt was greater in standing than in sitting and the posterior pelvic tilt was lesser in sitting than in standing. The anterior pelvic 
tilt in both sitting and standing was greater in the females than in the males. However, the effect of sex on the posterior pelvic tilt was only significant in sitting, but not in standing. The range of pelvic tilt was greater in sitting but not significantly affected by the sex. The pelvic tilt motion in these young adults demonstrated fairly large variability and the testing position and sex must be considered when assessing the pelvic tilt motion in a clinical setting.

\section{ACKNOWLEDGEMENTS}

This research was partially supported by the Academic Research Fund of Hoseo University in 2018 (\#20180342).

\section{CONFLICTS OF INTEREST}

No potential conflict of interest relevant to this article was reported.

\section{REFERENCES}

\section{Zawadka M, Skublewska-Paszkowska M, Gawda P, Lukasik E,} Smolka J, Jablonski M. What factors can affect lumbopelvic flexion-extension motion in the sagittal plane?: a literature review. Hum Mov Sci 2018;58:205-18.

2. Chun SW, Lim CY, Kim K, Hwang J, Chung SG. The relationships between low back pain and lumbar lordosis: a systematic review and meta-analysis. Spine J 2017;17(8):1180-91.

3. Janda V, Jull GA. Muscles and motor control in low back pain: assessment and management. In: Twomey LT, Taylor JR editors. Physical therapy of the low back. New York: Churchill Livingstone; 1987;253-78.

4. Laird RA, Gilbert J, Kent P, Keating JL. Comparing lumbopelvic kinematics in people with and without back pain: a systematic review and meta-analysis. BMC Musculoskelet Disord 2014; 15:229.

5. Day JW, Smidt GL, Lehmann T. Effect of pelvic tilt on standing posture. Phys Ther 1984;64(4):510-6.

6. Walker ML, Rothstein JM, Finucane SD, Lamb RL. Relationships between lumbar lordosis, pelvic tilt, and abdominal muscle performance. Phys Ther 1987;67(4):512-6.

7. Nguyen AD, Shultz SJ. Sex differences in clinical measures of lower extremity alignment. J Orthop Sports Phys Ther 2007;37(7):389-98
8. Herrington L. Assessment of the degree of pelvic tilt within a normal asymptomatic population. Man Ther 2011;16(6):6468.

9. Chen YL, Lin WC, Chen Y, Wen YW, Yan SQ, Tsai TL. Effect of wearing jeans on the back muscle flexion-relaxation phenomenon. Int J Ind Ergon 2020. [Epub]. https://doi.org/10.1016/ j.ergon.2020.102938.

10. Filardi V. Stress shielding in the bony chain of leg in presence of varus or valgus knee. J Orthop 2014;12(2):102-10.

11. Oh YC, Cynn HS, Yi CH, Jeon HS, Yoon TL. Effect of hip external rotation angle on pelvis and lower limb muscle activity during prone hip extension. Phys Ther Korea 2014;21(3):110.

12. Kang SY, Kim SH, Ahn SJ, Kim YH, Jeon HS. A comparison of pelvic, spine angle and buttock pressure in various crosslegged sitting postures. Phys Ther Korea 2012;19(1):1-9.

13. Jandre Reis FJ, Macedo AR. Influence of hamstring tightness in pelvic, lumbar and trunk range of motion in low back pain and asymptomatic volunteers during forward bending. Asian Spine J 2015;9(4):535-40.

14. McGregor AH, Hukins DW. Lower limb involvement in spinal function and low back pain. J Back Musculoskelet Rehabil 2009;22(4):219-22.

15. Levine D, Whittle MW. The effects of pelvic movement on lumbar lordosis in the standing position. J Orthop Sports Phys Ther 1996;24(3):130-5.

16. Nourbakhsh MR, Moussavi SJ, Salavati M. Effects of lifestyle and work-related physical activity on the degree of lumbar lordosis and chronic low back pain in a Middle East population. J Spinal Disord 2001;14(4):283-92.

17. Harrison DE, Harrison DD, Troyanovich SJ, Harmon S. A normal spinal position: it's time to accept the evidence. J Manipulative Physiol Ther 2000;23(9):623-44.

18. Granata KP, Orishimo KF. Response of trunk muscle coactivation to changes in spinal stability. J Biomech 2001;34(9): 1117-23.

19. Khamis S, Yizhar Z. Effect of feet hyperpronation on pelvic alignment in a standing position. Gait Posture 2007;25:12734.

20. Azevedo DC, Santos H, Carneiro RL, Andrade GT. Reliability of sagittal pelvic position assessments in standing, sitting and during hip flexion using palpation meter. J Bodyw Mov Ther 2014;18(2):210-4.

21. Gajdosik RL, Hatcher CK, Whitsell S. Influence of short ham- 
string muscles on the pelvis and lumbar spine in standing and during the toe-touch test. Clin Biomech (Bristol, Avon) 1992;7(1):38-42.

22. Zhou J, Ning X, Fathallah F. Differences in lumbopelvic rhythm between trunk flexion and extension. Clin Biomech (Bristol, Avon) 2016;32:274-9.

23. Vazirian M, Shojaei I, Bazrgari B. Age-related differences in the timing aspect of lumbopelvic rhythm during trunk motion in the sagittal plane. Hum Mov Sci 2017;51:1-8.

24. Pinto RZ, Souza TR, Trede RG, Kirkwood RN, Figueiredo EM, Fonseca ST. Bilateral and unilateral increases in calcaneal eversion affect pelvic alignment in standing position. Man Ther 2008;13(6):513-9.

25. Alqhtani RS, Jones MD, Theobald PS, Williams JM. Investigating the contribution of the upper and lower lumbar spine, relative to hip motion, in everyday tasks. Man Ther 2016;21:268-73.

26. Fasuyi FO, Fabunmi AA, Adegoke BOA. Hamstring muscle length and pelvic tilt range among individuals with and without low back pain. J Bodyw Mov Ther 2017;21(2):246-50.

27. Norris CM, Matthews M. Correlation between hamstring muscle length and pelvic tilt range during forward bending in healthy individuals: an initial evaluation. J Bodyw Mov Ther 2006;10(2):122-6.

28. Kienbacher T, Paul B, Habenicht R, Starek C, Wolf M, Kollmitzer J, et al. Age and gender related neuromuscular changes in trunk flexion-extension. J Neuroeng Rehabil 2015;12:3.

29. Marshall PW, Mannion J, Murphy BA. Extensibility of the hamstrings is best explained by mechanical components of muscle contraction, not behavioral measures in individuals with chronic low back pain. PM R 2009;1(8):709-18.

30. Raftry SM, Marshall PW. Does a 'tight' hamstring predict low back pain reporting during prolonged standing? J Electromyogr Kinesiol 2012;22(3):407-11.

31. Kuszewski MT, Gnat R, Gogola A. The impact of core muscles training on the range of anterior pelvic tilt in subjects with increased stiffness of the hamstrings. Hum Mov Sci 2018;57:32-9.

32. Carregaro RL, Gil Coury HJC. Does reduced hamstring flexibility affect trunk and pelvic movement strategies during manual handling? Int J Ind Ergon 2009;39(1):115-20. 